\title{
ENERGY ASSESSMENT TECHNIQUE FOR RETROFIT MINE- WATER DISTRICT HEAT NETWORK
}

\author{
B. Philip ${ }^{1 *}$, J. Littlewood ${ }^{2}$, R. Radford ${ }^{2}$, N. Evans ${ }^{2}$, T. Whyman ${ }^{2}$, D.P. Jones ${ }^{1}$ \\ ${ }^{1}$ SPECIFIC, Swansea University, Swansea, West Glamorgan
}

\author{
${ }^{2}$ Sustainable \& Resilient Built Environment (SuRBE) Group, Cardiff Metropolitan University, Cardiff, South Glamorgan \\ * Corresponding author
}

\begin{abstract}
UK buildings and energy infrastructures are heavily dependent on natural gas, a large proportion of which is used for space heating. Much of the UKs' gas is imported, therefore a wholesale shift in energy provision is required in order to meet government targets for reducing carbon emissions and improving energy security, without impacting on thermal comfort levels, convenience or cost of supply to the end user.

Heat pumps are a potential alternative for modern well insulated homes, however this is not necessarily true of a large proportion of British housing stock which was built prior to 1919. Increasing energy efficiency of older properties remains a significant challenge, which cannot be achieved through insulation and air-tightness interventions alone.

This paper investigates the energy demand of pre-1919 dwellings using a holistic surveying approach to provide a more accurate assessment of total household heat demand, and reports on the analysis of eight properties. This information is used to assess the feasibility of using water from disused mine workings to supply a heat pump based, district heat network. The use of renewable solar energy generation and storage technologies, to reduce the heat load and offset increased electricity demand, are also considered.
\end{abstract}

\section{Introduction}

The so called energy trilemma, of decarbonisation, increasing security of supply and reducing the cost of energy, is a major policy driver in the UK. Heat accounts for nearly half of the energy consumed in the UK and about a third of carbon emissions (Future heat series part 1). Peak gas demand in the winter exceeds electricity use by around five times, which means it will not be possible to deliver UK carbon reduction targets while gas remains the primary source of energy for heating. Substitution of gas heating with direct electrical heating is currently not an option, as there is insufficient capacity in the electrical generation and distribution grid to meet the demand, therefore alternative solutions are needed.

Since 2009 tens of millions of pounds have been invested to improve the energy performance of Welsh homes through a combination of measures including solid wall insulation, solar panels and upgrades to gas boilers and glazing (Arbed programme). In spite of these efforts, recent estimates by the Welsh government suggest that $23 \%$ of households in Wales spend more than $10 \%$ of income on energy bills and are thereby considered to be in fuel poverty (Fuel poverty). Many socioeconomic factors contribute to this figure, however the problem is exacerbated by the age and consequent poor energy performance of much of the housing stock in Wales and the UK as a whole.

Caerau, in the Bridgend County Borough Council (BCBC) region, was a once proud and prosperous coal mining village, but is now one of the most deprived communities in Wales. The majority of properties in the village were built in the early 1900s to meet the growing demand for labour in the local colliery, which operated from $1889-1979$ and at its peak employed 2400 workers.

$\mathrm{BCBC}$ sought a solution for heating the current community of approximately 7000 inhabitants, while simultaneously addressing the energy trilemma. There were no sources of waste heat to be exploited in the area, however the practicality of using water from the extensive network of former colliery workings as the basis for a district heating network was deemed worthy of further investigation.

Measurements from an exploratory bore hole found the temperature of the mine water to be over $20^{\circ} \mathrm{C}$ at $220 \mathrm{~m}$ depth. Large volume pumping tests have yet to be completed, therefore the volume of water available and expected temperature drop for a network supplying between 150 and 850 households is currently unknown. However initial indications are that mine water could provide a better temperature source 
than the $11^{\circ} \mathrm{C}$ that would be expected from a standard ground source heat pump and bore hole.

The feasibility of using either a centralised or decentralised heat pump network to provide heat to properties in Caerau was explored. In the centralised model, one or more large heat pumps would be used to heat water at the point where it was extracted from the mine workings, the hot water would then be circulated around the village in insulated pipes buried underground. Heat exchangers in houses connected to the district heat network would transfer the thermal energy to a separate hot water circuit to supply the household heating system. The cooled water would then flow back to the heat pump(s) above the mine via a return loop.

The decentralised model would operate similarly however in this instance the water would circulate around the village in uninsulated pipes at the temperature that it came out of the mine and would be heated by individual household heat pumps.

Domestic units with thermal outputs of $3 \mathrm{~kW}$ or $6 \mathrm{~kW}$ were considered. Both the centralised and decentralised models would require installation of an insulated hot water tank, if not already present in the property.

Initial calculations showed the cost of the centralised model to be significantly greater than the decentralised model and potential for heat loss from the system to be higher. Hence the decentralised model was selected as the preferred option, therefore requiring space for both a heat pump and storage tank in properties connected to the network.

This paper discusses the methodology adopted to provide a clear appraisal of the current heat demand of existing housing stock in Caerau, using a suite of investigative techniques, to enable correct sizing of heat pumps and the proposed heat network. The potential for retrofitting novel, renewable energy and demand management technologies that could complement the proposed district heat network are also considered.

\section{Methodology}

A range of complimentary techniques were employed to assess heat loss and the level of fabric insulation present, comprising:

- Internal and external measured surveys

- $\quad$ Schedule of condition survey

- $\quad$ Air permeability testing

- Thermography studies

The information was collated and used to calculate heat loss and heat transfer coefficients based on the methodology from the Standard Assessment Procedure (SAP) 2012, version 9.92 (SAP 2012).

Thermography was used to highlight major sources of heat loss and air leakage and to identify any potential problems associated with ingress of damp and / or thermal bridging. False colour thermal maps, or thermograms, were produced and thermally tuned prior to analysing the results. In order to conduct a meaningful thermographic survey certain environmental conditions need to be met: a minimum temperature difference of $10^{\circ} \mathrm{C}$ between the inside and outside of the building, no precipitation during the survey, surfaces should be dry, a maximum wind speed of $10 \mathrm{~m} / \mathrm{s}$, and no direct solar radiation on the surfaces for at least one hour prior to the survey. There is also a requirement to be cautious when interpreting thermograms where objects could be reflecting the night sky (Pearson, C. 2011).

A visual inspection of the services within the properties was made, with particular emphasis on the heating infrastructure and whether gas, electricity, or a combination of the two were used for internal temperature control. Where available, data from installed gas and electricity smart meters was collected to compare predicted heat loss figures with actual energy consumption.

A preliminary assessment of the town identified a limited number of residential typologies with the majority being approximately one hundred years old. BCBC provided a shortlist of residents who had expressed an interest in having their homes surveyed. Due to time and budgetary constraints a subset of those properties were selected to provide a representative cross section of building thermal performance. The eight properties discussed in this paper were all built prior to 1919 , two storeys and of solid wall construction, with varying amounts insulation. Due to the non-destructive nature of the assessment, some assumptions had to be made as to the construction materials used in certain areas of houses that have been altered or extended over the years.

\section{Results}

\subsection{Condition survey}

The condition survey involved an internal and external measured survey of each property and the production of dimensioned sketches of the floor plans and the elevations. A summary of the type of information captured in the schedule of conditions for one of the properties is as follows:

Traditional Welsh 3 bed mid-terraced house of solid wall construction and with a single storey extension containing the bathroom and kitchen to the rear. Extension is of solid wall construction.

Some thermal upgrades have been undertaken, with modern UPVC double glazed windows, and insulation applied to the attic spaces. Insulated plasterboard has been applied to the bathroom. Central heating throughout with a reconditioned 
condensing boiler and older style single panel pressed steel radiators.

The condition of the property is generally moderate. Property has notable damp and ventilation issues, leading to significant black mould growth in some areas of the property.

Table 1 provides a summary of the property types surveyed, size and current levels of fabric insulation, i.e. loft, External Wall Insulation (EWI) and Internal Wall Insulation (IWI).

The area of exposed external wall is a key contributor to the overall thermal performance of a building; from this perspective the properties presented fall into three categories based on the number of external walls; detached - four walls (property a), semi-detached and end terrace - three walls (properties b to d) and mid terrace - two walls (properties e to h). None of the properties surveyed met the recommended minimum level of loft insulation, which is $270 \mathrm{~mm}$ of mineral wool quilt (or equivalent).

Table 1 Condition Survey Summary Data

\begin{tabular}{|c|c|c|c|c|}
\hline $\begin{array}{l}\text { Property } \\
\text { Title }\end{array}$ & $\begin{array}{l}\text { Property } \\
\text { Type }\end{array}$ & $\begin{array}{l}\text { No. } \\
\text { Beds }\end{array}$ & $\begin{array}{l}\text { Floor } \\
\text { Area } \\
\left(\mathrm{m}^{2}\right)\end{array}$ & $\begin{array}{l}\text { Current } \\
\text { Insulation }\end{array}$ \\
\hline $\mathrm{a}$ & Detached & 5 & 159 & $100 \mathrm{~mm}$ loft \\
\hline $\mathrm{b}$ & $\begin{array}{c}\text { Semi- } \\
\text { detached }\end{array}$ & 4 & 91 & $\begin{array}{l}\text { EWI, IWI \& } \\
200 \mathrm{~mm} \text { Loft }\end{array}$ \\
\hline $\mathrm{c}$ & $\begin{array}{l}\text { End } \\
\text { terrace }\end{array}$ & 4 & 116 & Loft $200 \mathrm{~mm}$ \\
\hline d & $\begin{array}{l}\text { End } \\
\text { terrace }\end{array}$ & 3 & 87 & $100 \mathrm{~mm}$ Loft \\
\hline e & $\begin{array}{c}\text { Mid } \\
\text { terrace }\end{array}$ & 3 & 85 & EWI to rear \\
\hline $\mathrm{f}$ & $\begin{array}{l}\text { Mid } \\
\text { terrace }\end{array}$ & 3 & 78 & $80 \mathrm{~mm}$ loft \\
\hline $\mathrm{g}$ & $\begin{array}{c}\text { Mid } \\
\text { terrace }\end{array}$ & 3 & 92 & Loft (partial) \\
\hline $\mathrm{h}$ & $\begin{array}{l}\text { Mid } \\
\text { terrace }\end{array}$ & 2 & 71 & $\begin{array}{c}\text { EWI \& 80mm } \\
\text { loft (partial) }\end{array}$ \\
\hline
\end{tabular}

All but one of the properties used a natural gas combination boiler as the primary source for space heating. The detached house had recently been fitted with an air source heat pump. In all cases the size of the central heating radiators would need to be increased in order to deliver heat effectively from a lower temperature, heat pump based system.

\subsection{Air permeability}

The air permeability tests were performed using a single fan blower door, in accordance with the Technical Standard L1 from the Air Tightness Testing and Measurement Association (ATTMA 2016). Tests were undertaken within the permitted conditions, i.e. less than six meters per second for the wind speed, all external doors and windows closed, all internal doors open, flues and air vents temporarily sealed and gas boilers switched off (if present). Calculated air permeability values are presented in Table 2. All properties surveyed were below the current maximum allowable air permeability value for dwellings in UK building regulations of $10 \mathrm{~m}^{3} / \mathrm{h} \cdot \mathrm{m}^{2} @ 50 \mathrm{~Pa}$ (Building Regs 2010).

\subsection{Heat loss}

The heat loss and heat transfer coefficients were calculated according to the standard assessment procedure (SAP 2012), inputting data from the measured survey and air permeability test results. Average annual values are presented in Table 2. Comparing the results of properties $b$, e and $h$ with others in the same categories, the higher thermal resistance afforded by the retrofitted EWI is reflected in the lower average heat transfer coefficient and average heat loss parameters. Properties $\mathrm{g}$ and e had conservatories within the normally heated zone, which increase the thermal losses from these properties.

Table 2 Results of air permeability, average heat transfer and average heat loss parameter

\begin{tabular}{cccc}
\hline $\begin{array}{c}\text { Property } \\
\text { Title }\end{array}$ & $\begin{array}{c}\text { Air } \\
\text { Permeability } \\
\mathrm{m}^{3} / \\
\left(\mathrm{h} . \mathrm{m}^{2}\right) @ 50 \mathrm{~Pa}\end{array}$ & $\begin{array}{c}\text { Average Heat } \\
\text { Transfer } \\
\text { Coefficient } \\
(\mathrm{W} / \mathrm{K})\end{array}$ & $\begin{array}{c}\text { Average } \\
\text { Heat Loss } \\
\text { Parameter } \\
\left(\mathrm{W} / \mathrm{m}^{2} \mathrm{~K}\right)\end{array}$ \\
\hline $\mathrm{a}$ & 4.1 & 653 & 4.1 \\
$\mathrm{~b}$ & 5.7 & 213 & 2.4 \\
$\mathrm{c}$ & 8.0 & 392 & 3.4 \\
$\mathrm{~d}$ & 7.3 & 387 & 4.5 \\
$\mathrm{e}$ & 8.5 & 232 & 2.7 \\
$\mathrm{f}$ & 6.5 & 239 & 3.1 \\
$\mathrm{~g}$ & 7.6 & 294 & 3.2 \\
$\mathrm{~h}$ & 8.1 & 162 & 2.3 \\
\hline
\end{tabular}




\subsection{Thermography}

Both external and internal qualitative thermographic surveys were conducted to assess the thermal performance of the dwellings. Two thermograms and associated digital images from a mid terraced property, are presented in Figure 1 and Figure 2. The property presented had EWI applied to the rear of the house but not on the dressed stone frontage. Heat loss from the building is indicated by colder colours (dark blues and black) for internal surveys and by warm colours (yellows, reds and white) for external surveys. These are referred to as thermal anomalies.

Figure 1 Thermographic image of the interior of a typical pre-1919 solid wall traditional Welsh mining house

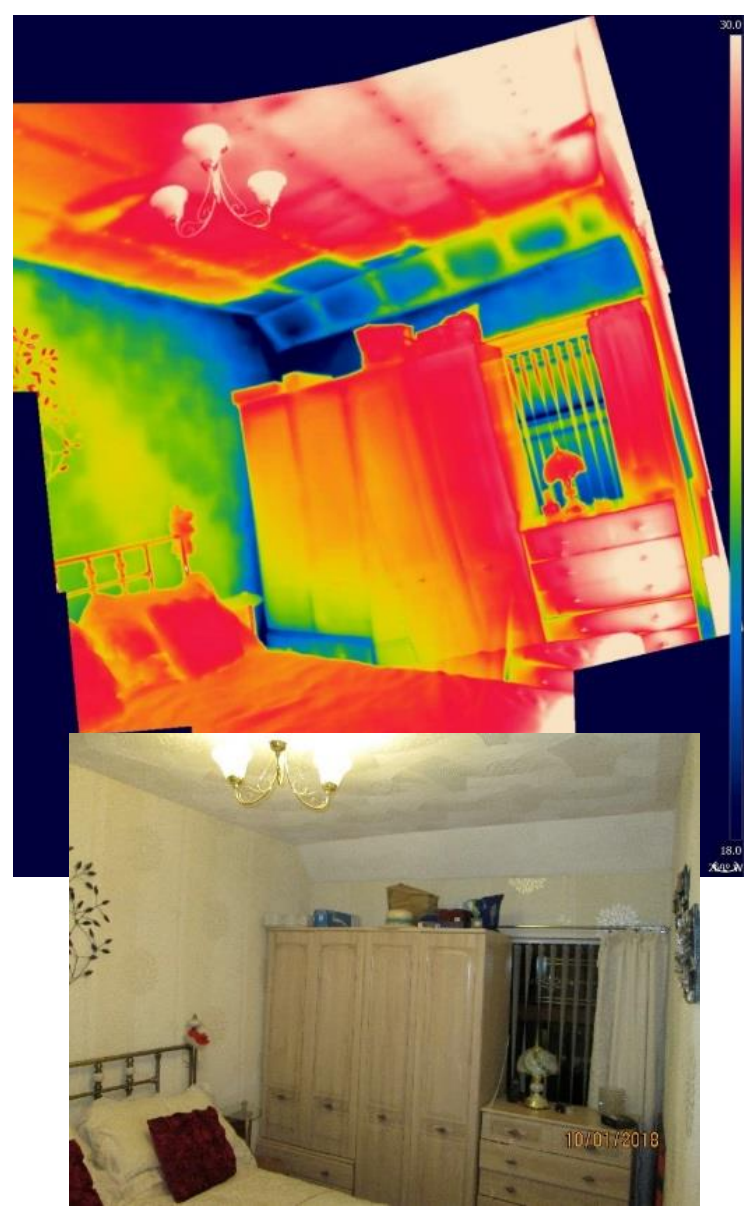

The thermogram in Figure 1 shows considerably higher heat loss through the uninsulated, dressed stone exterior wall to the front of the property, above the window. The coldest area is in the upper left hand corner above the wardrobe, where humidity levels may be higher due to a lack of air circulation. Heat loss along the raked ceiling at the wall junction may be the result of poor or missing insulation. Thermal bridging at the roof joists is also visible. Heat loss via conduction to the exterior wall and loft space is evident from the cool blue colour at the junction between the party wall (left), the ceiling and the front exterior wall. (Thermogram temperature scale $18^{\circ} \mathrm{C}-30^{\circ} \mathrm{C}$ ).

The thermogram in Figure 2 shows the rear wall of the same pre-1919 property, with recently installed EWI (left of image). The internal temperature of the property was $26^{\circ} \mathrm{C}$ and the external temperature was $3^{\circ} \mathrm{C}$. The cool blue colours of external wall insulation to the rear of the house shows reduced thermal transfer to the external environment. This is highlighted by red colour of the property to the right of the image, which has no external insulation; while the right hand property was not part of the survey, it is unlikely that the internal temperature was higher than $26^{\circ} \mathrm{C}$.

Figure 2 Thermographic image of the rear of a pre-1919 traditional Welsh mining house with more recent extensions and EWI

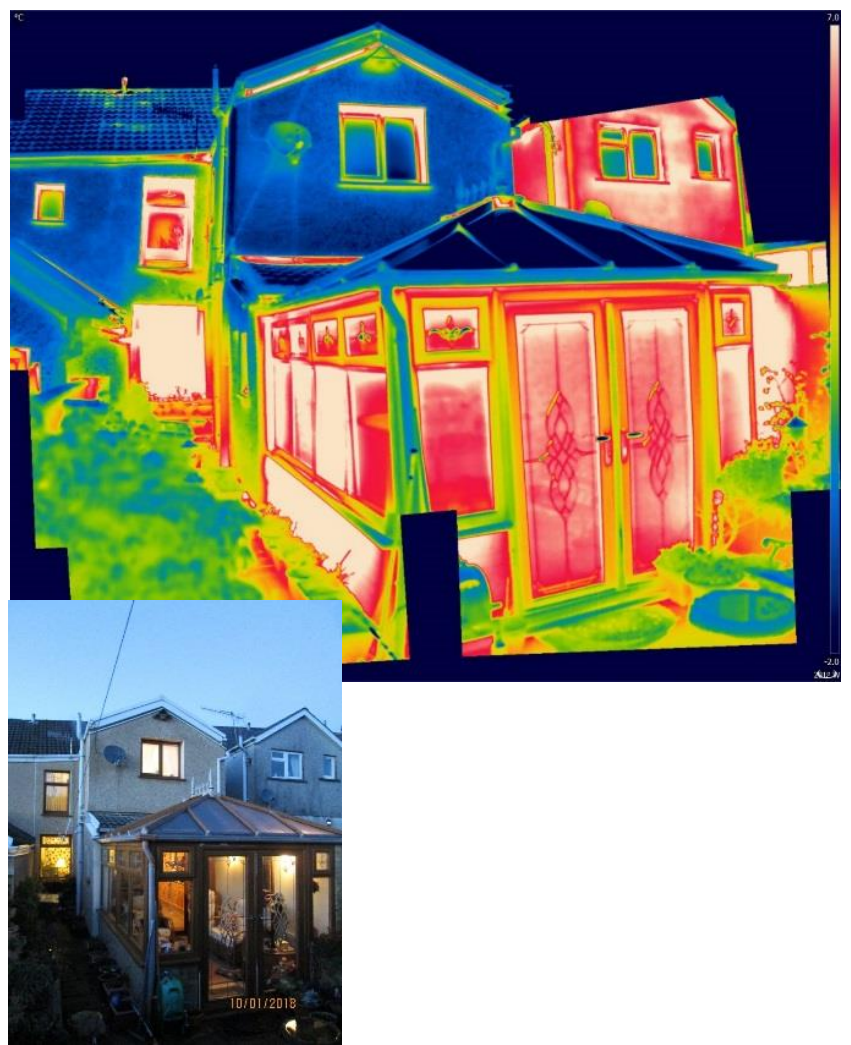

Higher heat loss is evident by the white and red areas around the window frames, at the junctions between the walls and roof, and where the two story extension meets the roof of the single story extension. This highlights the challenge of retrofitting EWI around junctions and reveals and the need for careful detailing in order to avoid thermal bridging. The heated conservatory exhibits high levels of heat loss. (Thermogram temperature scale $-2^{0} \mathrm{C}-7^{0} \mathrm{C}$ ).

\subsection{Energy consumption}

Smart meters provide a useful source of historic gas and electricity consumption data. Unfortunately, few of the properties surveyed had smart meters fitted and in certain properties with smart meters, the data were not sufficiently detailed to enable meaningful analysis to be conducted. The reasons for this would appear to be twofold: 
1. Energy suppliers can take monthly readings, however the consumer must volunteer to enable daily or half hourly data collection.

2. In order to collect data, the smart meter requires a good wireless connection; if the signal is poor (as is often the case in solid stone properties), or interrupted, consumption for the period will be estimated.

An analysis method for data retrieved from a property with half-hourly data is presented. Total energy usage in monthly, daily or half hourly increments, dating back to June 2016 was made available. Space heating in the property was provided exclusively by means of a mains gas boiler, hence, electrical consumption was ignored. By averaging the consumption data over the summer months (1st June - 30 September 2016), typical gas consumption for cooking and domestic water heating outside the heating season could be estimated. This value was subtracted from the overall gas consumption through the winter months, to provide an estimate for the gas consumed for space heating purposes only. From this data the graph of daily gas consumption for heating is illustrated in Figure 3.

Average external temperature readings from the nearest weather station (St Athan weather station (Weather underground)) were plotted on the same axis, along with the Heating Degree Days. Heating Degree Days (HDD) are used for calculations relating to the energy consumption required to heat buildings. They provide a measure of the level (in degrees) and duration (in days) that the external air temperature falls below the set point at which the heating system of a building is switched on. This is known as the "base temperature". For example, if the base temperature is $16^{\circ} \mathrm{C}$ and the average external temperature over a 24 -hour period is $14^{\circ} \mathrm{C}$, this is equivalent to two HDDs. For the most part, good correlation between HDD's and gas consumption for heating is observed, albeit with some scatter from day to day.

Figure 3 Plot of daily heating gas consumption (kWh), external temperature and heating degree days

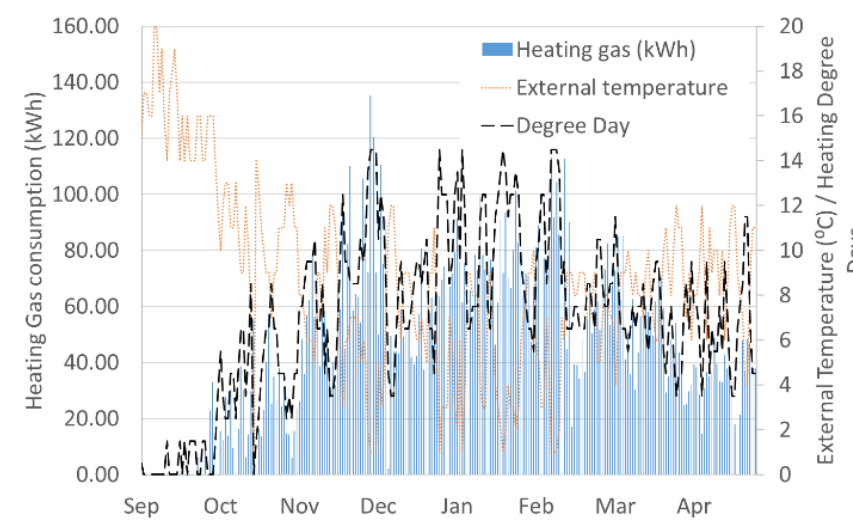

In order to provide a clearer view of the relationship between the HDD and energy (gas) consumption, the daily data were aggregated to provide weekly totals. These values were then plotted against one another over a period when space heating was in constant use, from the 1 st October 2016 to the 30th April 2017 (Figure 4). A linear regression analysis was applied to determine the HDD base temperature that provided the line of best fit, which was $15.9^{\circ} \mathrm{C}$ in this instance; close to the UK average of $15.5^{\circ} \mathrm{C}$ (Carbon Trust. 2017).

Figure 4 Linear regression analysis of heating gas consumption

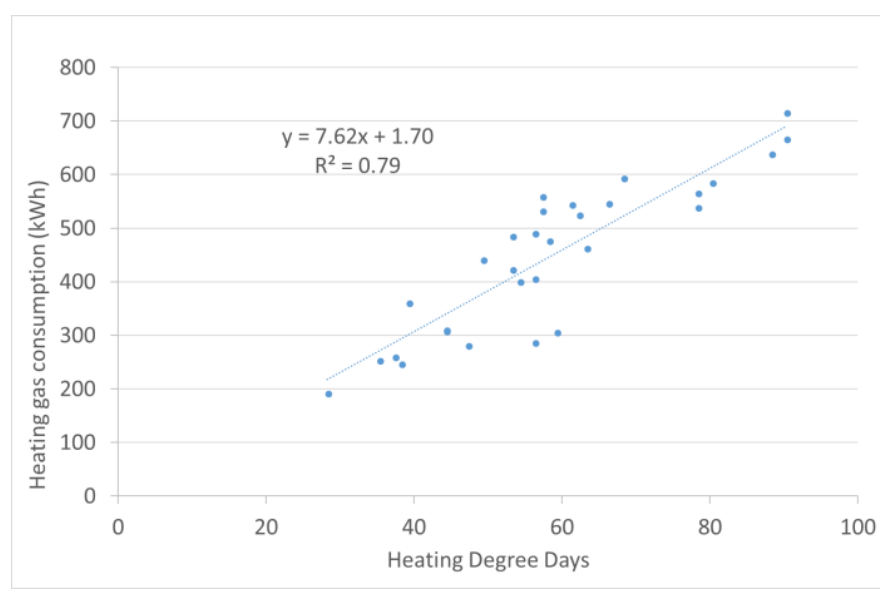

The resulting equation for heating gas energy for the property is given below (1):

Energy $(\mathrm{kWh})=7.6 \times$ HDD $)+1.7$

A comparison of the predicted heating energy from the heat loss calculations (SAP) and the metered heating gas usage is shown in Figure 5. The predicted energy usage was calculated from the monthly heat transfer coefficient $(\mathrm{W} / \mathrm{K})$, converting the power values to units of energy $(\mathrm{kWh})$, according to equation (2) (where $\mathrm{T}$ is temperature):

$\mathrm{kWh}=\frac{\left(\left(\frac{\mathrm{W}}{\mathrm{K}}\right) \times(\text { days in month }) \mathrm{x}(24 \mathrm{hrs}) \mathrm{x}(\text { base T }- \text { Av. Ext. T })\right)}{1000}$

Two sets of temperature data were used:

1. Average temperature data for Wales provided for use in SAP calculations (SAP 2012)

2. Local (St Athan) temperature data for the months in question (Weather underground)

The data show the predicted heat loss to be a good approximation for the actual heating requirements of the property, with slightly closer correlation to local weather data than the averaged SAP temperature values. Metered gas consumption figures are generally lower than heat loss predictions; which is to be expected, as the shortfall could be made up through a combination of incidental heat gains from lighting, cooking, electrical appliances, human activity and 
passive solar gains, although a certain amount of underheating, due to financial constraints, may be a contributory factor.

Figure 5 Comparison between actual gas consumption and predicted energy usage from SAP calculations

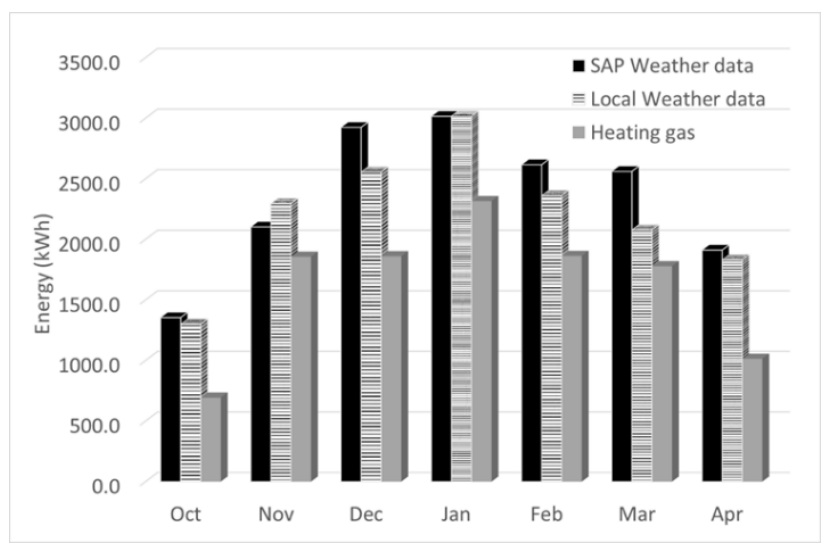

\subsection{Peak heating load}

Using the heat transfer coefficient figures from Table 2 and assuming a maximum internal to external temperature difference of $24^{\circ} \mathrm{C}$ (assuming an inside temperature of $21^{\circ} \mathrm{C}$ and a worst case external temperature of minus $3^{\circ} \mathrm{C}$ ), the peak heat demand for the properties can be estimated. These are presented in Table 3 . These values can be used to size the heat pumps required for a distributed heat pump network and the level of additional insulation that would be required to reduce the heat loads below a given threshold for connection to the network.

The beneficial effect of additional insulation is highlighted by the current peak loads for properties b and d, which are $5.1 \mathrm{~kW}$ and $9.1 \mathrm{~kW}$ respectively. Property $\mathrm{b}$ has EWI applied to two of the three exterior walls; the dressed stone front wall was not insulated, potentially due to planning restrictions. Internal insulation was also installed in the lounge. Property d had no EWI and minimal loft insulation.

A calculation of the theoretical peak heating loads that could be achieved with a high degree of thermal intervention was simulated by adjusting SAP calculations to include triple glazing throughout the properties, $250 \mathrm{~mm}$ of EWI on all external walls and $350 \mathrm{~mm}$ of loft insulation. The results are presented in Table 3. The larger detached, semi-detached and end terrace properties which have more uninsulated external wall area, show the greatest improvement, as would be expected. These levels of thermal intervention are unlikely to be achievable in practice for a number of reasons:

1. Planning restrictions prohibiting application of EWI to the dressed stone frontages that characterise Welsh mining houses and are therefore considered of historic importance.

2. Space constraints where access around properties and in attic spaces would be reduced to unacceptable levels and rerouting of existing services may not be possible.
3. Economics: the costs rise linearly with increasing insulation thickness, while the net benefit diminishes (Figure 6). Similarly, the thermal performance improvement of replacing good quality double glazing with triple glazing is small relative to the cost.

Table 3 Estimated peak heat load

\begin{tabular}{cccc}
\hline $\begin{array}{c}\text { Property } \\
\text { Title }\end{array}$ & $\begin{array}{c}\text { Average } \\
\text { Heat } \\
\text { Transfer } \\
\text { Coefficient } \\
(\mathrm{W} / \mathrm{K})\end{array}$ & $\begin{array}{c}\text { Current } \\
\text { Peak } \\
\text { Heating } \\
\text { Load }(\mathrm{kW} \\
\text { for } \\
\left.\Delta \mathrm{T}=24^{0} \mathrm{C}\right)\end{array}$ & $\begin{array}{c}\text { Peak Heating } \\
\text { Load after } \\
\text { Interventions } \\
(\mathrm{kW} \text { for } \\
\left.\Delta \mathrm{T}=24^{0} \mathrm{C}\right)\end{array}$ \\
\hline a & 653 & 15.6 & 5.4 \\
$\mathrm{~b}$ & 213 & 5.1 & 3.4 \\
$\mathrm{c}$ & 392 & 9.4 & 3.8 \\
$\mathrm{~d}$ & 387 & 9.1 & 3.8 \\
$\mathrm{e}$ & 232 & 5.5 & 3.3 \\
$\mathrm{f}$ & 239 & 5.7 & 2.6 \\
$\mathrm{~g}$ & 294 & 7.0 & 3.3 \\
$\mathrm{~h}$ & 162 & 3.9 & 2.4 \\
\hline
\end{tabular}

Figure 6 illustrates the reduction in U-value for retrofitting increasing thickness of expanded polystyrene EWI to a solid wall property with a starting, uninsulated U-value of $2.4 \mathrm{~W} / \mathrm{m}^{2} \mathrm{~K}$. The plot shows an order of magnitude reduction in U-value for $150 \mathrm{~mm}$ of EWI, thereafter the reductions are ever more marginal.

Figure 6 Plot of thermal performance (U-Value) against increasing insulation thickness

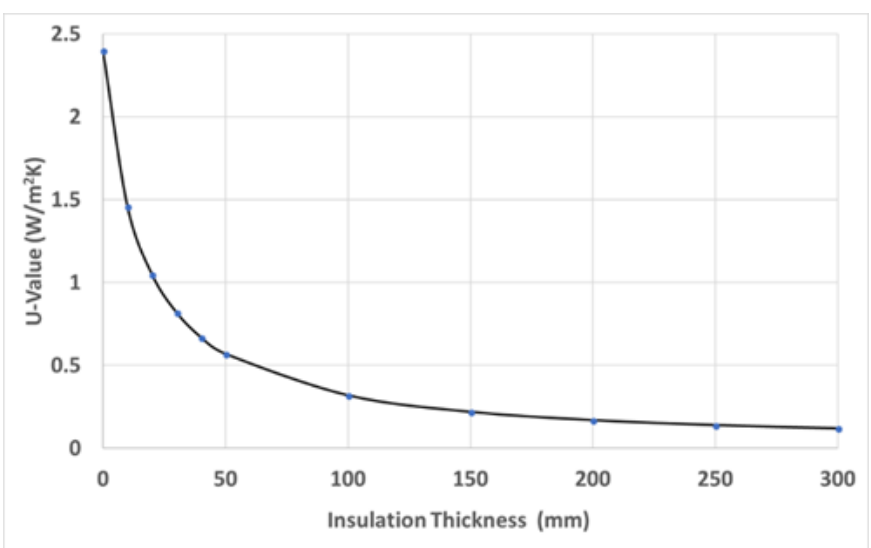




\section{Discussion}

\subsection{Insulation}

By far the greatest opportunity for reducing the heat demand for space heating is to retrofit additional wall and loft insulation. The advantages of loft insulation and the importance of maintaining ventilation to roof joists in the unheated space above, are well understood.

The advantages of exterior wall insulation as opposed to interior wall insulation include: reduced risk of thermal bridging, improved air tightness, thermal mass remains exposed to the internal space to aid control of summer overheating risks, less disruption to occupants, no loss of internal floor area, and internal fixtures and fittings do not have to be relocated (An introduction to low carbon domestic refurbishment 2010. Energy Efficiency in Historic Buildings 2010, King C, Weeks C, 2010. Immendoerfer A et al. 2008. Littlewood J et al. 2015).

Achieving a complete covering of exterior wall insulation at critical junctions to prevent all thermal bridging can be challenging, including: window and door reveals, wall to roof junctions, any projections such as porches and conservatories and where adjoining buildings meet (as illustrated in Figure 2) (An introduction to low carbon domestic refurbishment 2010. Energy Efficiency in Historic Buildings 2010. Immendoerfer A et al. 2008). Thermal bridging can lead to increased heat loss and thus a reduction in the overall thermal performance, along with internal surface condensation due to localised lower surface temperatures (Ward T. 2006). To address surface condensation resulting from thermal bridging, occupants can either: increase the internal air temperature to raise the internal surface temperature above the dew point temperature of the air; or increase the rate of ventilation to reduce the dew point temperature of the air to below the dew point temperature of the internal surface (Atkinson J, 2015). However, with either, or a combination of these approaches, energy use will be increased in order to maintain comfort levels (Burberry, P. 1997), which will undermine the overall effectiveness and purpose of the insulation.

There are a range of insulation materials and systems available for use in retrofit of exterior walls; the most common materials used are moisture impermeable polymer foams. Given the age and construction of the properties surveyed, the use of vapour permeable exterior wall insulation (e.g. wood fibre, hemp, wool, etc.) may be a better long-term solution and would confer better end of life credentials. By enabling the passage of water vapour, problems associated with interstitial condensation and associated damp issues could be avoided.

Planning restrictions may prohibit insulation of the front exterior walls of traditional houses as the dressed stone would be hidden and, in many instances, insulation would encroach onto the public pavement.

\subsection{Ventilation}

Several of the properties surveyed showed signs of damp. These presented as condensation on the internal surfaces of some external walls and black mould growth in the corners of certain rooms and behind furniture, where air movement was limited. Increasing ventilation improves indoor air quality and the wellbeing of occupants by providing more oxygen for breathing, removing exhaled carbon dioxide, diluting pollutants / odours and reducing moisture build up and associated damp and mould issues. The most obvious and common approach to increasing ventilation is to open a window, however this carries with it an energy and cost penalty, as cold fresh air enters the building at the expense of warm air escaping. Several suppliers offer products which aim to provide greater ventilation while minimising energy losses. Examples include:

- Wall mounted, single room Mechanical Ventilation and Heat Recovery (MVHR) units which provide a continuous supply of fresh air which is preheated by the outgoing stale air.

Demand controlled ventilation; where air flow is adjusted by moisture sensitive air vents which open automatically depending on room humidity.

Retrofitting EWI would be expected to reduce uncontrolled air infiltration, which should be compensated for by additional controlled ventilation. The air permeability test results for properties b and d, (5.70 and 7.27 m $/ \mathrm{h} . \mathrm{m}^{2} @ 50 \mathrm{~Pa}$ respectively, Table 2) demonstrate this. This was not the case for the two mid terraced houses which had EWI applied. In both cases poorly finished penetrations for services lead to higher air permeability figures than would have been expected.

\subsection{Renewable integration}

Based on a heat pump with $6 \mathrm{~kW}$ thermal output and rated electrical power consumption of $1.6 \mathrm{~kW}$, the additional load on the local electricity network as a result of transferring the space heating load from gas to electricity would equate to $0.24 \mathrm{MW}$ for 150 connected homes, or $1.36 \mathrm{MW}$ for 850 homes. The impact on the electricity network and the carbon equivalent of the heating solution could be reduced through incorporation of local renewable energy generation and storage.

The orientation of the streets in Caerau and the overall topography of the village, in a broad valley which runs approximately South West to North East, lends itself to solar energy generation.

The roof area of a typical terraced residence in Caerau is sufficient to accommodate approximately $3 \mathrm{~kW}$ (peak) of crystalline silicon Photo Voltaic (PV) panels. A system of this size would provide a predicted total annual generation of $2770 \mathrm{kWh}$, based on historical climatic data for the region. Storing this energy for later use could lower grid stress by removing spikes in demand and offset utility costs, particularly if time of use tariffs were introduced. 
Electrical storage in batteries is one option. Battery sizing is specific to individual usage patterns and is a trade-off between cost and how much generation can be usefully captured. Too large a battery will have redundant capacity for much of the year, cost more and be physically larger. Broadly speaking, typical domestic electrical energy consumption is in the region of $10 \mathrm{kWh} /$ day. On a clear summer's day, peak generation from the PV array could be considerably greater than consumption. Conversely, on a cloudy winter day, there may be little or no generation. A battery capacity in the region of $3-5 \mathrm{kWh}$ might therefore be a sensible compromise. The space required for the system would be approximately the size of a standard airing cupboard.

Solar Thermal Generation - Solar air heating is an effective means of supplying pre-warmed fresh air to a building. Glazed solar collectors are available which are entirely passive; using an inbuilt solar cell to drive a fan that only operates when air in the panel is heated by the sun. Prewarmed air is ducted into the house and can be controlled thermostatically, or by a simple on/off switch. Perforated steel thermal panels based on the 'SolarWall' design have no glazing and are most commonly associated with industrial or commercial applications, however domestic variants are available. Outputs of 200 $250 \mathrm{kWh} /$ year $/ \mathrm{m}^{2}$ area are claimed for South facing walls.

Solar thermal technologies are hampered by the fact that they are most efficient in the summer when additional heat is least required. However, they can provide a useful boost to air temperature, particularly in the spring and autumn, where external air temperatures are fluctuating around the level at which space heating is required and solar irradiance can be relatively high.

Solar thermal water heaters such as evacuated tube, flat plate collector systems are, as the name implies, designed for heating water. As hot water is required year-round they can take advantage of higher summer efficiencies. Modern, well insulated hot water tanks also enable storage of thermal energy for several hours. Such a tank is likely to be specified for use in conjunction with a heat pump system, if not already installed. As a rule of thumb, a $1 \mathrm{~m}^{2}$ collector area per person will supply $50 \%$ of a typical families' hot water requirement (up to $100 \%$ in the summer, with secondary heating system required in the winter).

Commercially available 'Heat Batteries' use excess electricity from PV generation to heat a phase-change material. Once heated the storage material is held as a liquid in tanks. When hot water is required, unheated water from a mains supply flows through heat exchangers in the device and heat is transferred to it by an exothermic reaction as the storage material changes from liquid to solid form. The on-demand system is capable of delivering water at $55{ }^{\circ} \mathrm{C}$, meaning there is no need for a water storage tank. The energy density of the material is greater than water and thermal losses are lower, therefore the unit is more compact and can store energy for longer.
Interseasonal heat storage would revolutionise the heating industry, enabling thermal energy from the summer or waste heat from industrial processes to be delivered in the winter. There are no commercially available systems at present, however research into thermochemical materials which undergo a fully reversible chemical reaction are showing great promise (SPECIFIC IKC).

Local planning restrictions and competition for space with PV panels may limit the type and location of solar thermal generation. A solar thermal water heating system would require additional pipework, increasing the potential for leaks and present ongoing maintenance considerations. An alternative approach would be to divert surplus electrical generation from PV panels to a water immersion heater or 'heat battery' thereby storing thermal energy for later use. A variety of commercial solar PV immersion diverters are available.

\subsection{Barriers to connection}

There are a number of potential barriers that could impede connection of properties to the heat network; most of these are concerned with routing and access and, while challenging, they are not seen as insurmountable. Within the property alterations to existing infrastructure, e.g. increasing the size of radiators, would be required. However, the major barrier is one of available space. The heat pump and storage tank would require a space the size of a conventional airing cupboard (approximately $900 \mathrm{~mm} \times 900 \mathrm{~mm}$ ). Battery storage and associated infrastructure would require a similar amount of space.

Some of the properties assessed are relatively small and all have had various alterations to the internal layout over the past century, therefore the available space varies from one to the next. In the event that the properties were to be fitted with a heat pump, thermal storage and electrical battery storage, coupled to locally generated renewable energy, the available space to accommodate all of the necessary equipment within the property may be insufficient. Most of the properties in Caerau have land to the rear, but little or no frontage. Once again, the space available to the rear varies dependent on the size of extensions and number of additional outbuildings that have been added over the years, however, a small, exterior 'plant room' may be a viable option for housing additional heating/battery infrastructure in certain cases.

\section{Conclusion}

A wholistic method for assessing household heating energy demand was presented. Retrofit of thermal efficiency interventions to reduce the overall heat demand of pre-1919 solid wall properties to a level where a mine water-based heat network would be capable of provide the primary heating mechanism, were investigated. Complimentary renewable solar energy generation and storage technologies that could further reduce heat pump load, offset additional stress on the local electrical distribution grid and alleviate household electricity bills were considered. 
In general, mid terraced houses have the lowest peak heat demand, followed by end-terraced/semi-detached and then detached properties; as would be expected with increasing exposed external wall area. The peak heating loads calculated for each of the eight properties, based on a $24^{\circ} \mathrm{C}$ difference between exterior and interior temperature, demonstrate the range between a maximum of $15.6 \mathrm{~kW}$ for a large detached property, to a minimum of $3.9 \mathrm{~kW}$ for a mid-terrace house with front and rear EWI. Two properties with the highest levels of loft insulation were still $70 \mathrm{~mm}$ below the minimum recommended in UK building regulations of $270 \mathrm{~mm}$ of quilted mineral wool. The peak heat loads demonstrate the impact of additional loft and wall insulation. These figures indicate that with sensible levels of fabric insulation, heat loss from the properties can be reduced to a level whereby a heat pump with thermal output of $6 \mathrm{~kW}$ (electrical input $1.6 \mathrm{~kW}$ ) could provide the primary heat source. The theoretical reductions in peak heating demand presented in Table 3 show that the level of EWI and loft insulation necessary to reach a lower target of $3 \mathrm{~kW}$ are unlikely to be achievable in practice.

Tight control over the quality of detailing of any EWI needs to be exercised to avoid thermal bridging and water ingress, as observed in the conditional and thermographic surveys. In particular, consideration should be given to extending the roof line to ensure a good and permanent seal at the interface between wall and insulation. A moisture permeable EWI may be more appropriate for solid walled buildings in order to avoid problems arising from interstitial condensation and subsequent dampness which could inadvertently degrade the property over time. Planning restrictions may preclude the installation of EWI on dressed stone frontages.

Comparing actual gas consumption with energy losses calculated using SAP appeared to show good agreement, however a larger sample would be required to confirm this.

Clear signs of dampness from a combination of water ingress and insufficient ventilation were apparent in several properties. Somewhat perversely, this problem can be exacerbated by the addition of EWI, which has the effect of reducing uncontrolled air infiltration and increasing temperature variations on internal wall through poor detailing. Appropriate measures to increase ventilation rates should be taken in tandem to ensure that, in striving for increased energy efficiency, the health and wellbeing of residents is not compromised. A combination of solar thermal air heaters and controlled ventilation could help to reduce the risk of condensation on cold surfaces. Orientation / planning restrictions may preclude the use of wall mounted panels on certain houses.

The favourable orientation of the properties in Caerau lends itself to local generation from PV panels, which would help to offset increased electricity bills without impacting greatly on internal space. Electrical storage in batteries would require additional internal space, however lightweight lithium batteries could potentially be housed in the attic alongside inverters and charge controllers, to avoid encroaching on living space. They would have the longest return on investment, though the economic argument would change if time of use tariffs were introduced. Depending on the base load of the property, surplus electrical generation from PV panels could be diverted into an immersion heater, to store thermal energy in a hot water tank or 'heat battery'; this would present a cost-effective and space efficient means of storing PV energy while simultaneously reducing the heat load of the property. Solar water heater panels could be utilised, however they would compete for roof space with PV panels, and add to system complexity and ongoing maintenance. Products which combine PhotoVoltaic and Thermal generation (PV-T) have recently come onto the market; however, it is not currently known how their performance compares to separate PV and solar thermal panels.

There are a number of technical and economic challenges to enable the use of a mine water district heat network, however with careful consideration and selection of complementary technologies and close control over quality during installation the desired outcome could be achieved.

\section{Acknowledgements}

The authors would like to thank the Engineering and Physical Sciences Research Council - EPSRC, Innovate UK (formerly the Technology Strategy Board) and the Welsh Assembly Government for the financial support of this work. SPECIFIC and Cardiff Metropolitan University for preparing the data, and Bridgend County Borough Council for agreeing to share the findings.

\section{References}

Future heat series part 1 - Pathways for heat, Carbon Connect http://www.policyconnect.org.uk/cc/sites/site_cc/files/report/ 505/fieldreportdownload/carbonconnectpathwaysforheatwebc opy.pdf (accessed 21/11/2018)

Arbed programme

https://gov.wales/topics/environmentcountryside/energy/effici ency/warm-homes/arbed/?lang=en (accessed 20/11/2018)

Fuel poverty

https://gov.wales/topics/environmentcountryside/energy/fuelp overty/?lang=en (accessed 21/11/2018)

SAP 2012 https://www.bre.co.uk/filelibrary/SAP/2012/SAP2012_9-92.pdf (accessed 6/6/2018)

Pearson, C. 2011. Thermal Imaging of Building Fabric: BSRIA, ISBN 9780860227052

ATTMA. 2016. Technical Standard L1, September 2016 edition. $\quad$ See: https://www.attma.org/wpcontent/uploads/2016/09/ATTMA-TSL1-Issue-3-Rev-02016.09.09.pdf (accessed 13/11/2018)

Building Regs 2010

https://assets.publishing.service.gov.uk/government/uploads/s 
ystem/uploads/attachment_data/file/697629/L1B_secure1.pdf

Carbon Trust. 2017. Degree days for Energy Management: https://www.carbontrust.com/media/137002/ctg075-degreedays-for-energy-management.pdf

Weather underground: www.wunderground.com

Littlewood J et al. 2015. Did ARBED I Save Energy in Wales' Deprived Dwellings? Energy Procedia Journal. Volume 83, December 2015, Pages 444-453

Immendoerfer A et al. 2008. Fit for the Future: The Green Homes Retrofit Manual - Technical Supplement. London: Housing Corporation

An introduction to low carbon domestic refurbishment 2010. Construction Products Association. See: https://www.barbourproductsearch.info/CPA-Low-CarbonDomestic-Refurbishment-file017103.pdf

Energy Efficiency in Historic Buildings - Insulating Solid Walls 2010. English Heritage. http://eprints.sparaochbevara.se/617/1/Insulating_solid_walls. pdf

King C, Weeks C, 2010. Sustainable Refurbishment of NonTraditional Housing and Pre-1920's Solid Wall Housing. Watford: IHS BRE Press

Ward T. 2006. Information Paper 1/06: Assessing the effects of thermal bridging at junctions and around openings. Watford: BRE

Atkinson J, 2015. Evaluating exterior wall insulation. Unpublished PhD Thesis. Cardiff Metropolitan University, Cardiff, UK

Burberry, P. 1997. Environment and Services. Eighth Edition. Essex: Pearson Education Limited

SPECIFIC IKC

http://www.specific.eu.com/technologies\#shgs 